Pak. j. sci. ind. res. Ser. B: biol. sci. 2020 63B(3) 142-147

\title{
Comparative Fatty Acids Analysis of Delonix regia and Tetrapleura tetraptera
}

\author{
Abdul Ademola Olaleye ${ }^{a *}$ and Habibat Omolara Adubiaro ${ }^{b}$ \\ ${ }^{a}$ Department of Chemistry, Faculty of Science, Federal University Dutse, Jigawa State, Nigeria \\ ${ }^{b}$ Department of Chemistry, Faculty of Science, Federal University Oye-Ekiti, Ekiti State, Nigeria \\ (received January $1^{\text {st }}, 2018$; revised January 23, 2019; accepted January 29, 2019)
}

\begin{abstract}
Fatty acid levels of two edible and medicinal species: Delonix regia and Tetrapleura tetraptera seeds flour were investigated using standard analytical techniques. Among the saturated fatty acids (SFA), palmitic acid (17.2-49.4\%) had the highest concentration in both samples. Oleic acid (19.7-21.0\%) was most abundant among the mono-unsaturated fatty acids (MUFA). In both samples, palmitoleic acid recorded $0.00 \%$ concentration, whilst margaric acid (0.001-0.060\%), lignoceric acid (0.001-0.079\%) and arachidonic acid $(0.065-0.080 \%)$ were found in trace amounts. Both samples were high in total poly-unsaturated fatty acids (PUFA) (26.9-42.7\%). MUFA/SFA was less than 1.00 in both samples (0.375-0.584); PUFA/SFA was 1.18 (Delonix regia) and 0.507 (Tetrapleura tetraptera). Total unsaturated fatty acid (TUFA) (63.8\%) was higher than total SFA(36.1\%) in Delonix regia. In Tetrapleura tetraptera, SFA (53.1\%) was more than TUFA (46.8\%). 2n-6/3n-3 were high at 59.9 (Delonix regia) and 536 (Tetrapleura tetraptera). The correlation coefficient of the fatty acids was positively high and significant.
\end{abstract}

Keywords: fatty acids, gold mohur, aidan, correlation

\section{Introduction}

Gold mohur (Delonix regia) belongs to the Caesalpiniaceae family (family: Leguminosae, subfamily: Fabaceae). The generic name "Delonix" is derived from Greek delos (visible) and onyx (claw); an allusion to the conspicuously clawed petals. The specific name "regia" is from the Latin word regis (royal, regal, magnificient). It is an ornamental medium-sized tree, noted for its fern-like leaves and flamboyant display of flowers. The tree is known to reach heights of approximately $12 \mathrm{~m}$, whereas the flowers, which cover the tree crown, show colours ranging from orange to red. In Africa, extracts of the flower are used to produce a traditional health beverage which contains the phenolic acids: gallic acid, protocatechuic acid and 2-hydroxy 5-[(3,4,5 trihydroxyphenyl) carbonyl oxy] benzoic acid. Carotenoids and anthocyanins are responsible for the vibrant colours observed in the petals of the flower (Veigas et al., 2012). It is a species of flowering plant in the family Fabaceae. It has many names: Arabic (goldmore), English (flamboyant flame tree, gold mohur), German (Feuerbaum), French (royal, Poinciana) and Yoruba (sekeseke). It is widespread in most tropical and subtropical areas of the world especially in all warm and damp parts of India. Delonix regia has a superficial

*Author for correspondence; E-mail: lebdul@yahoo.com root system and competes favourably with the neighbouring shrubs and flowering plants.

Aidan tree (Tetrapleura tetraptera) is a medicinal plant of the family Mimosaceae. It is widely found in the lowland forest of tropical Africa. It has a distinctive four winged fruits comprising of woody shell, fleshy pulp and small brownish-black seeds with a characteristic distinct fragrance which is attributed to the essential oil content of the fruit (Akin-Idowu et al., 2011). The dry fruit has a characteristic pleasant aroma which makes it a popular spice in southern and eastern Nigeria (Okwu, 2003). In addition to its main uses in the management of various ailments such as diabetes mellitus, epilepsy and asthma (Akin-Idowu et al., 2011), convulsions inflammation and rheumatism (Okwu, 2003). The fruits also serve as multivitamins to the Ghanaians, while Nigerians and other west African countries use Tetrapleura tetraptera as spice (Adewumi, 2001).

The whole world is currently facing problem of poor nutrition and is getting worse on daily basis (Ackman, 1989). Food security has been a crucial issue in most developing countries of the world especially in Africa. People need to consume adequate calories and nutrients to overcome the problem of malnutrition. There is little literature information on the nutrients profile, especially fatty acid composition of gold mohur and aidan seeds. The aim of this report is to investigate the fatty acid 
composition of these samples. This is to further enhance their nutritional usefulness in Food industry.

\section{Materials and Methods}

Sample collection and preparation. The samples were obtained from Erekesan market in Ado-Ekiti, Ekiti state, Nigeria and were later identified in the Department of Plant Science, Ekiti State University, Ado-Ekiti. They were screened to eliminate the defective ones. The samples were then dried in an oven at $45^{\circ} \mathrm{C}$ and drymilled separately to fine powder, stored in a cool, dry place prior to use for analyses as described below. Twenty-two seeds each were used for the analyses.

Determination of ether extract. An aliquot (0.25 g) of each sample was weighed in an extraction thimble and $200 \mathrm{~mL}$ of petroleum ether $\left(40-60^{\circ} \mathrm{C}\right.$ boiling range) was added. The covered thimble with the sample was extracted for five hours using Soxhlet extractor. The extracted fat, almost free of petroleum ether was removed from the heating mantle, oven dried at $105^{\circ} \mathrm{C}$ for one hour, cooled in a desiccators and the weight of dried oil was determined.

The fatty acid methyl ester analysis. $50 \mathrm{mg}$ of the extracted fat content of the sample was saponified for 5 min at $95{ }^{\circ} \mathrm{C}$ with $3.4 \mathrm{~mL}$ of $0.5 \mathrm{MKOH}$ in dry methanol. The mixture was neutralized by using 0.7 $\mathrm{MHCl} .3 \mathrm{~mL}$ of $14 \%$ boron trifluoride in methanol was added. The mixture was heated for five minutes at 90 ${ }^{\circ} \mathrm{C}$ to achieve complete methylation process. The fatty acid methyl esters were thrice extracted from the mixture with redistilled n-hexane. The content was concentrated to $1 \mathrm{~mL}$ for gas chromatography analysis and $1 \mu \mathrm{L}$ was injected into the injection port of gas chromatograph (GC).

GC conditions for the analysis of fatty acid methyl esters. GC: HP6890 powered with HP Chem Station rev. A 09.01[1206] software; Injection type, split injection split ratio: 20:1 and carrier gas is nitrogen; inlet temperature $=250^{\circ} \mathrm{C}$, Column type $=\mathrm{HP}$ INNOWAX; column dimensions $=30 \mathrm{~m} \times 0.25 \mathrm{~mm} \times 0.25 \mu \mathrm{m}$

Oven programme. Initial temperature at $60{ }^{\circ} \mathrm{C}$. First ramping at $10^{\circ} \mathrm{C} / \mathrm{min}$ for $20 \mathrm{~min}$, maintained for $4 \mathrm{~min}$. Second ramping at $15{ }^{\circ} \mathrm{C} / \mathrm{min}$ for $4 \mathrm{~min}$, maintained for $10 \mathrm{~min}$; Detector $=$ FID (Flame ionization detector); detector temperature $=320^{\circ} \mathrm{C}$; hydrogen pressure $=22$ psi; compressed air $=35$ psi
Statistical analysis. Statistical analysis (Oloyo, 2001; Chase, 1976) was carried out to determine mean, standard deviation (SD), coefficient of variation percent $(\mathrm{CV} \%)$. Also calculated were linear correlation coefficient $\left(\mathrm{r}_{\mathrm{xy}}\right)$, coefficient of determination or variance $\left(\mathrm{r}_{\mathrm{xy}}{ }^{2}\right)$, coefficient of alienation (CA) and index of forecasting efficiency (IFE). The $r_{x y}$ was subjected to the table (critical) value at $r=0.05$ to see if significant differences existed in the values of fatty acids between the two samples and other parameters calculated from the fatty acid data.

\section{Results and Discussion}

Fatty acid composition. The percent levels of various fatty acids in the samples are depicted in Table 1. Fat has been described to be the major portion of man's energy supplies, giving weight-for-weight more than twice as much energy as proteins or carbohydrates (Osborne and Voogt, 1978). Just as the proportion of carbohydrate in the human diet is influenced by ecological and economic factors, level of fat is also influenced by the same factors (Osborne and Voogt, 1978). The most concentrated fatty acids in this study are (\% level in gold mohur and Aidan respectively): palmitic (17.2 and 49.9), oleic acid (21.0 and 19.7) and linoleic acid (41.9 and 26.8). Many of the fatty acids in gold mohur were higher than those in aidan seeds; in gold mohur, lauric acid, myristic acid, stearic acid, margaric acid, arachidic acid, behenic acid, lignoceric acid and $\alpha$-linolenic acid had (\%) 0.149, 0.345, 9.00, $0.060,4.19,5.09,0.079$ and 0.711 respectively, while

Table 1. Fatty acid composition of gold mohur and aidan seeds flour(\% total fatty acid)

\begin{tabular}{llllll}
\hline \hline Fatty acid & $\begin{array}{l}\text { Gold } \\
\text { mohur }\end{array}$ & Aidan & Mean & SD & CV\% \\
\hline Lauric acid & 0.149 & 0.00 & 0.075 & 0.105 & 140 \\
Myristic acid & 0.345 & 0.011 & 0.178 & 0.236 & 133 \\
Palmitic acid & 17.2 & 49.4 & 33.3 & 22.8 & 68.5 \\
Stearic acd & 9.00 & 3.20 & 6.10 & 4.10 & 67.2 \\
Margaric acid & 0.060 & 0.001 & 0.031 & 0.042 & 135 \\
Arachidic acid & 4.19 & 0.023 & 2.11 & 2.95 & 140 \\
Behenic acid & 5.09 & 0.442 & 2.77 & 3.29 & 119 \\
Lignoceric acid & 0.079 & 0.001 & 0.040 & 0.055 & 138 \\
Palmitoleic acid & 0.00 & 0.00 & 0.00 & 0.00 & 0.00 \\
Oleic acid & 21.0 & 19.7 & 20.4 & 0.919 & 4.50 \\
Erucic acid & 0.080 & 0.243 & 0.162 & 0.115 & 71.0 \\
Linoleic acid & 41.9 & 26.8 & 34.5 & 10.7 & 31.0 \\
\&-linolenic acid & 0.711 & 0.050 & 0.381 & 0.467 & 123 \\
Arachidonic acid 0.065 & 0.080 & 0.073 & 0.011 & 15.1 \\
\hline \multicolumn{7}{l}{ Total } & 100 & 100 & 100 & 0.00 & 0.00 \\
\hline \hline
\end{tabular}


the corresponding percentage values in aidan were 0.00 , $0.011,3.20,0.001,0.023,0.442,0.001$ and 0.050 respectively.

The following saturated fatty acids (SFAs), lauric acid (12:0), myristic acid (14:0), palmitic acid (16:0), stearic acid (18:0), margaric acid (17:0), arachidic acid (20:0), behenic acid (22:0) and lignoceric acid (24:0) were all detected at various levels. Palmitic acid (17.2-49.4\%) was the most concentrated SFA in both samples. Palmitic acid has been reported to be the most concentrated SFA in nature: three different fish samples (22.3-23.5\%) (Olaleye et al., 2014), grains of treated sorghum bicolour (16.6-18.3\%) (Adeyeye and Adesina, 2013), groundnut seeds (10.1-13.0\%) (Adeyeye and Agesin, 2012), melon seeds flour (9.54-10.8\%) (Adeyeye and Olaleye, 2015) and different cereals consumed in Nigeria (millet, maize, sorghum and rice) (10.9-21.0\%) (Adeyeye and Ajewole, 1992). Both myristic and palmitic acids were reported to raise low density lipoproteins bonded cholesterol (LDL-C) relative to oleic acid, but myristic acid was slightly more deleterious (Zock et al., 1994). It is interesting to note that the levels of myristic acid (0.011$0.345 \%$ ) were low in both samples. Relative to carbohydrates, the saturated fatty acids had been observed to elevate serum cholesterol. However, stearic acid (18:0) may not be as hyper cholesterolemic as others as it is readily converted to oleic acid in the body metabolism. It is worthy of note that saturated fatty acids have some beneficial effects in nutrition. SFA constitutes at least $50 \%$ of the cell membranes giving our cells stiffness and integrity and for calcium to be effectively incorporated into the skeletal structure, at least $50 \%$ of the dietary fats should be saturated (Watkins et al., 1996). Saturated fatty acids also enhance the immune system by protecting the liver from negative effects of alcohol and other toxins such as Tylenol, they have antimicrobial properties, protecting us from harmful micro-organisms in the digestive tract (Dahlen et al., 1998). The fat around the heart muscle is highly saturated due to high concentration of palmitic and stearic acids and the heart draws on this fat reserve in times of stress (Daley et al., 2010). Oleic acid (C18:1) (Cis-9) was most abundant among the mono-unsaturated fatty acids (MUFAs) in the samples with values ranging from 19.7$21.0 \%$ and $\mathrm{CV} \%$ of 4.50 , indicating the closeness of their values and the Palmitoleic acid recorded zero percent concentration in both samples. Mono-unsaturated fatty acids reduce the risk of coronary heart diseases (CHD) when compared with saturated fatty acids,
MUFAs lower total cholesterol and low density lipoprotein (LDL) cholesterol levels and relative to carbohydrates, MUFAs increase high density lipoprotein (HDL) cholesterol levels. Individuals with elevated insulin also may benefit from a high mono-unsaturated fatty acid diet (Kris-Etherton, 1999). Linoleic acid was high in both samples and was equally the most abundant poly-unsaturated fatty acid (PUFA) with values ranging between $41.9 \%$ (gold mohur) and $26.8 \%$ (aidan). The levels of linoleic acid (n-6) in this study were comparatively lower than $58.9-60.7 \%$ in three varieties of melon seeds (Adeyeye and Olaleye, 2015) and 67.7\% in edible ant eggs (Virginia et al., 2013). Also the present C18:2 (n-6) fatty acid levels were higher than 7.52-9.07 $\%$ reported for three fresh water fish samples (Olaleye et al., 2014), 8.1\% reported for the larva of Cirinia forda (Akinnawo and Ketiku, 2000) and 13.9-20.9 \% in Vigna subterranea seed parts (Adeyeye et al., 2015). Alpha linolenic acid (18:3, n-3) was higher in gold mohur $(0.711 \%)$ than aidan $(0.050)$, both values were comparatively lower than the following food sources: edible ant eggs (2.61\%) (Melo et al., 2013), melon seed flour (1.64-1.81\%) (Adeyeye and Olaleye, 2015), fresh water fish samples (1.17-1.30\%) (Olaleye et al., 2014). Diets rich in Omega-3 (n-3) linolenic acid had been observed to exert a significant anti coronary heart disease effect in humans both in clinical and epidemiological studies (Hayes, 2002).

Statistical analysis of Table 1. Table 2 presents the statistical analysis of the results from Table 1. The correlation coefficient $\left(\mathrm{r}_{\mathrm{xy}}\right)$ was positively high and significant at 0.7323 . The overall mean values were

Table 2. Statistical analysis of the results from Table 1

\begin{tabular}{llcl}
\hline \hline Statistics & Gold mohur & Aidan & \\
\hline$r_{\text {xy }}$ & 0.7323 & 0.5363 & \\
$r_{\text {xy }}{ }^{2}$ & & & 7.14 \\
Rxy & 7.13 & & \\
Mean & & & 14.8 \\
& 12.1 & & 207 \\
SD & 170 & 0.681 & \\
CV\% & & 0.319 & \\
CA & & $*$ & \\
IFE & & \\
Remark & & & \\
\hline \hline
\end{tabular}

$*=$ significant at $\mathrm{r}=0.05$ and $\mathrm{n}-2$ degree of freedom; $\mathrm{C}_{\mathrm{A}}$

= coefficient of alienation; IFE $=$ index of forecasting efficiency 
low in both samples at $7.14 \mathrm{~g} / 100 \mathrm{~g}$ (gold mohur) and $7.14 \mathrm{~g} / 100 \mathrm{~g}$ ) cp (aidan) with corresponding high coefficient of variation (CV \%) of 170 and 207. The coefficient of alienation (CA) or non-relationship was low at $0.681(68.1 \%)$ with low index of forecasting efficiency (IFE) of 0.319 (or $31.9 \%$ ). The IFE is a reduction in the error of prediction of relationship, here between the fatty acids of the two samples. The error of prediction of relationship in the samples would be $100-31.9=68.1 \%$; this means it would be difficult to predict the biochemical relationship in the samples.

Fatty acid summary. Table 3, presents the summary of the fatty acids into saturated, mono-unsaturated, poly-unsaturated (SFA, MUFA and PUFA respectively). MUFA/SFA, PUFA/SFA and 2n-6/3n-3 are also shown in Table 3.

The concentrations of total SFA were $36.1 \%$ (gold mohur) and 53.1\% (aidan). Some literature values for total SFA were: fresh water fish samples (35.0-38.1\%) (Olaleye et al., 2014); three insect larvae (22.4-35.9\%) (Olaleye et al., 2017). The total MUFA levels for the samples 19.9-21.1\% were lower than the following literature values: skin (24.0\%) and muscle (24.3\%) of Oreochromis niloticus (Adeyeye, 2011); fresh water fish samples (38.3-39.4\%) (Olaleye et al., 2014). The levels of total unsaturated fatty acid (TUFA) in the samples (46.8-63.8\%) were higher than $32.8-40.2 \%$ in six varieties of dehulled African yam bean (Sphenostylis stenocarpa) (Adeyeye et al., 1999) flour. The concentrations of MUFA and PUFA in gold mohur were comparatively higher than those in aidan.

The ratio of mono-unsaturated fatty acid to saturated fatty acid (MUFA/SFA) in the samples (0.375-0.584) indicated that SFA was more than MUFA in each of the samples. Christie (2011) reported that the relative proportion of SFA to MUFA is important in phospholipids composition and abnormal changes to this ratio have been claimed to have effects on disease states such as cardiovascular disease, obesity, diabetes, neuropathological condition and cancer. The level of PUFA/SFA in gold mohur (1.18) was higher than 0.507 in aidan. Literature values for PUFA/SFA ratios from other food sources are the fresh water fish samples (0.59-0.75) (Olaleye et al., 2014) and Vigna subterranea seed parts (1.65-2.50) (Adeyeye et al., 2015) and melon seed flour (2.76-4.25) (Adeyeye and Olaleye, 2015). PUFA/SFA ratio is important in determining the detrimental effects of dietary fats. Honatra (1974) observed that the severity of atherosclerosis is closely associated with the proportion of the total energy supplied by saturated fats and PUFA. Linoleic (2n-6) and alpha linolenic acid (3n-3) ratios (2n-6/3n-3) was high in gold mohur (58.9) and extremely high at 536 in aidan. The two essential fatty acids (EFAs) compete for similar metabolic enzymes and have different biological roles; the balance between them in the diets can be of considerable importance (WHO/FAO, 1994). Too much omega- 6 fatty acid in the diet causes an imbalance that could have interference with the production of important prost aglandins. Several clinical intervention studies support the view that decreasing the $n-6 / n-3$ fatty acids ratio results in an increased protection against degenerative diseases. The present $2 n-6: 3 n-3$ ratios showed that the samples contained too much more omega-6 compared to omega-3.

Statistical analysis of Table 3. The statistical analysis of the results shown in Table 3 is depicted in Table 4. The $r_{x y}$ was high, positive and significant. The mean, standard deviation (SD) and CV \% were high for both

Table 3. Summary of fatty acids into SFA, MUFA, PUFA and $2 n-6 / 3 n-3$ values (\% total fatty acid)

\begin{tabular}{llllll}
\hline \hline Fatty acid & $\begin{array}{l}\text { Gold } \\
\text { mohur }\end{array}$ & Aidan & Mean & SD & CV\% \\
\hline SFA & 36.1 & 53.1 & 44.6 & 12.0 & 26.9 \\
MUFA & 21.1 & 19.9 & 20.5 & 0.849 & 4.14 \\
PUFA & 42.7 & 26.9 & 34.8 & 11.2 & 32.2 \\
TUFA & 63.8 & 46.8 & 55.3 & 12.0 & 21.7 \\
MUFA/SFA & 0.584 & 0.375 & 0.480 & 0.148 & 30.8 \\
PUFA/SFA & 1.18 & 0.507 & 0.844 & 0.476 & 56.4 \\
2n-6/3n-3 & 58.9 & 536 & 297 & 337 & 113 \\
\hline \hline
\end{tabular}

Table 4. Statistical analysis of the results from Table 3

\begin{tabular}{llcc}
\hline \hline Statistics & Gold mohur & & Aidan \\
\hline $\mathrm{r}_{\mathrm{xy}}$ & 0.5411 & 0.2928 & \\
$\mathrm{r}_{\mathrm{xy}}{ }^{2}$ & & & \\
Mean & 32.1 & & \\
& & & 197.7 \\
$\mathrm{SD}$ & 25.6 & & 199 \\
$\mathrm{CV} \%$ & 79.8 & 0.841 & \\
$\mathrm{C}_{\mathrm{A}}$ & & 0.159 & \\
IFE & & $*$ & \\
Remark & & & \\
\hline
\end{tabular}

$*$ significant at $\mathrm{r}=0.05$ and $\mathrm{n}-2$ degree of freedom; $\mathrm{C}_{\mathrm{A}}$ $=$ coefficient of alienation; IFE $=$ index of forecasting efficiency 
samples but higher in aidan. While, the $\mathrm{C}_{\mathrm{A}}$ was high ( 0.841 or $84.1 \%)$, the IFE was low $(0.159$ or $15.9 \%)$ thereby making the prediction of relationship extremely difficult. The IFE result gave an indication that the biochemical functions of gold mohur may not be performed by aidan and vice versa.

Energy contribution. The contribution of energy by various fatty acid groups and their percentages are presented in Table 5. SFA contributed 1336-1965 $\mathrm{kJ} / 100 \mathrm{~g}$; MUFA (736-781 kJ/100g); PUFA (995-1580 $\mathrm{kJ} / 100 \mathrm{~g}$ ); TUFA (1732-2361 kJ/100g).

Research had shown that the intake of PUFAs by humans should not be greater than $4 \%$ of the caloric total (Lassarre et al., 1985); \% SFA (30\% E). The present results were higher than these values.

Statistical analysis of Table 5. Table 6 shows the statistical analysis of the results (kJ) from Table 5 . The $\mathrm{r}_{\mathrm{xy}}$ was positive, low and not significant. Both the mean and SD were extremely high and the $\mathrm{CV} \%$ in the two samples were close to each other. The value of coefficient

Table 5. Energy contributions by the various fatty acid groups

\begin{tabular}{lllllll}
\hline \hline Fatty acid & $\begin{array}{l}\text { Gold } \\
\text { mohur }\end{array}$ & Aidan & Mean & SD & CV\% \\
\hline SFA & $(\mathrm{kJ})$ & 1336 & 1965 & 1651 & 445 & 27.0 \\
& $(\mathrm{kcal})$ & 319 & 470 & 395 & 107 & 27.1 \\
MUFA (kJ) & 781 & 736 & 759 & 31.8 & 4.19 \\
& $(\mathrm{kcal})$ & 187 & 176 & 182 & 7.78 & 4.27 \\
PUFA & $(\mathrm{kJ})$ & 1580 & 995 & 1288 & 414 & 32.1 \\
& $(\mathrm{kcal})$ & 378 & 238 & 308 & 99.0 & 32.1 \\
TUFA & $(\mathrm{kJ})$ & 2361 & 1732 & 2047 & 445 & 21.7 \\
& $(\mathrm{kcal})$ & 564 & 414 & 489 & 106 & 21.7 \\
\hline \hline
\end{tabular}

Table 6. Statistical analysis of the results fromTable 5

\begin{tabular}{llll}
\hline \hline Statistics & Gold mohur & & Aidan \\
\hline $\mathrm{r}_{\mathrm{xy}}$ & & & 0.5565 \\
$\mathrm{r}_{\mathrm{xy}}{ }^{2}$ & & 0.3097 \\
$\mathrm{Rxy}$ & & \\
Mean & 1515 & & 1357 \\
$\mathrm{SD}$ & 656 & & 585 \\
$\mathrm{CV} \%$ & 43.3 & & 41.3 \\
$\mathrm{C}_{\mathrm{A}}$ & & 0.8308 & \\
$\mathrm{IFE}$ & & 0.1692 & \\
Remark & & $\mathrm{NS}$ & \\
\hline \hline
\end{tabular}

$\mathrm{NS}=$ Not significant at $\mathrm{r}=0.05$ and $\mathrm{n}-2$ degree of freedom; $\mathrm{C}_{\mathrm{A}}=$ coefficient of alienation; IFE $=$ index of forecasting efficiency. of alienation or lack of relationship (CA) was much higher than that of index of forecasting efficiency (IFE), showing that the reduction in the error prediction of relationship in biochemical functions between gold mohur and aidan samples was low.

\section{Conclusion}

Findings of this report showed linoleic acid as the major PUFA as well as the most concentrated fatty acid. Palmitic acid and oleic acid were the predominant SFA and MUFA respectively. Total unsaturated fatty acid was higher than total saturated fatty acid in Delonix regia, whereas in Tetrapleura tetraptera, SFA was more than TUFA. Most of the parameters determined were more concentrated in Delonix regia. The samples contained higher omega-6 (linoleic) fatty acid than omega-3 ( $\alpha$-linolenic) fatty acid and therefore should be supplemented with foods rich in omega-3. Generally, the samples are good sources of fatty acids, especially unsaturated fatty acids; therefore their consumption should be promoted.

Conflict of Interest. The authors declare no conflict of interest

\section{References}

Ackman, R.G.1989. Fatty acids. In: Marine Biogenic Lipids, Fats and Oils, pp. 145-178, Ackman, R.G. (eds.), CRC Press, Boca Raton, USA.

Adewumi, C.O. 2001. Potential Uses of Tetrapleura tetraptera (Taub). (Mimosaceae), 2913 p., Science Africa's First Online Margazine.

Adeyeye, E.I. 2011. Levels of fatty acids, phospholipids and sterols in the skin and muscle of Tilapia (Oreochromisniloticus) fish. La Rivista Italiana Delle Sostanze Grasse, 88: 46-55.

Adeyeye, E.I., Ajewole, K. 1992. Chemical composition and fatty acid profiles of cereals in Nigeria. Food Chemistry, 44: 41-44.

Adeyeye, E.I., Agesin, M.O. 2012. Effect of roasting and cooking on the lipid composition of raw groundnut (Arachis hypogaea) seeds: dietary implications. Elixir Food Science, 42: 6257-6266.

Adeyeye, E.I., Adesina, A.J. 2013. Enhancement of lipid quality of raw guineas corn (Sorghum bicolour) grains through germination and steeping. Open Journal of Analytical Chemistry Research, 1: 517.

Adeyeye, E.I., Olaleye, A.A. 2015. Lipid compositions 
of three varieties of melon seeds flour: Dietary and health implications. Journal of Chemical, Biological and Physical Sciences, 5: 3828-3841.

Adeyeye, E.I., Oshodi, A.A., Ipinmoroti, K.O. 1999. Fatty acid composition of six varieties of dehulled African yam bean (Sphenostylis stenocarpa) flour. International Journal of Food Science and Nutrition, 50: 357-365.

Adeyeye, E.I., Olaleye, A.A., Adesina, A.J. 2015. Lipid composition of testa, dehulled and whole seed of bambara groundnut (Vigna subterranean L. Verdc). Current Advances in Plant Sciences Research, 2: $1-9$.

Akinnawo, O., Ketiku, A.O. 2000. Chemical composition and fattyacid profile of edible larva of Cirinaforda (westwood). African Journal of Biomedical Research, 3: 93-96.

Akin-Idowu, P.E., Ibitoye, D.C., Ademogegun, O.T., Adeniyi, O.T. 2011. Chemical composition of dry fruit of Tetrapleura tetraptera and its potential impacts on human health. Journal of Herrb, Spices and Medicinal Plants, 17: 52-61.

Chase, C.I. 1976. Elementary Statistical Procedure, $2^{\text {nd }}$ edition, Mc Graw-Hill Kogahusha Ltd, Tokyo, Japan.

Dahlen, G.H., Srinivasan, S.R., Stenlun, H., Wattigney, W.A., Berenson, G.S., Wall, S. 1998. The importance of serum lipoprotein (a) as an independent risk factor for premature coronary artery disease in middle-age black and white women from United States. Journal of Internal Medicine, 244: 417424.

Daley, C.A., Abbort, A., Douley, P.S., Nader, G.A., Larson, S. 2010. Grassfed versus grainfed beef fatty acid profiles, antioxidant content and taste. Nutrtion Journal, 9: 10-21.

Hayes, K.C. 2002. Dietary fat and heart health: in search of the ideal fat. Asian Pacific Journal of Clinical Nutrition, 11: 5394-5400.

Honatra, G. 1974. Diatary fats and arterial thrombosis. Haemostasis, 2: 21-52.

Kris-Etherton, P.M. 1999. Mono unsaturated fatty acid and risk of cardiovascular disease. Circulation, 100: 1258 .

Lassarre, M., Mendi, F. Spielmann, D., Jacotot, B. 1985.
Effects of different dietary intake of essential fatty acids on C20:3n-6 and C20: 4n-6serum levels in human adults. Lipids, 20: 27-233.

Okwu, D.E. 2003. The potentials of Ocimum gratissimum, Pengularia extensa and Tetrapleura tetraptera as spices and flowering agents. Nigerian Agricultural Journal, 35: 143-148.

Olaleye, A.A., Ogungbenle, H.N., Ayeni, K.E. 2014. Mineral and fatty acid compositions of three fresh water fish samples commonly consumed in south western states of Nigeria. Elixir Food Science, 74: 26719-26723.

Olaleye, A.A., Adeyeye, E.I., Gbolagade, A.Y. 2017. Lipid profile of the larvae of snout beetle, scarab beetle and silkworm: dietary importance. Journal of Chemical, Biological and Physical Sciences, 7: 833-845.

Oloyo, R.A. 2001. Fundamentals of Research Methodology for Social and Applied Sciences. ROA Educational Press, Ilaro, Nigeria.

Osborne, D.R., Voogt, P. 1978. The Analysis of Nutrients in Foods. pp. 251, Academi Press, London.

Veigas, J.M., Divya, P., Neelwarne, B. 2012. Identification of previously unreported pigments among carotenoids and anthocyanins in floral petals Delonix regia (Hook). Food Research International, 47: 116-123.

Virginia, M.R., Karina, S.H., Horacio, S.T., Tomas, Q.B., Concepcion, C.C. 2013. Lipids data composition of edible ant eggs (Liometopum apiculatum). M. Escamoles. Journal of Life Sciences, 7: 547-552.

Watkins, B.A., Shen, C.L., Allen, K.G.D., Seifert, M.F. 1996. Dietary (n-3) and (n-6) polyunsaturated and acetyl asalicylic acid alter exvivo $\mathrm{PGE}_{2}$ biosynthesis, tissue 1GF-1 levels and bone morphometry in chicks. Journal of Bone and Mineral Research, 1: 1321-1332.

(WHO/FAO), 1994. Fats and oils in human nutrition (Report of a joint $\mathrm{FAO} / \mathrm{WHO}$ expert consultaion food and nutrition), pp147.

Zock, P.L., Devries, J.H., Katam, M.B. 1994. Impact of myristic acid versus palmitic acid on serum lipid and lipoprotein levels in healthy women and men. Artioscier Thrombosis, 14: 567-575. 